UDC 629.735.33.02-027.3:658.51.011.46

JEL Classification: 014, P47, R49

DOI: $10.15587 / 2706-5448.2020 .215691$

Vorobiov Iu.,
Maiorova K.

\title{
DEVELOPMENT OF METHODS FOR ASSESSING THE ECONOMIC EFFECT OF USING A COMPLEX IMPULSE TECHNOLOGIES AND EOUIPMENT FOR AGGREGATE ASSEMBLY STRUCTURE OF THE AIRCRAFT
}

The object of the study is the economic effect of using a set of pulse technologies and equipment for unit assembly of aircraft structures with fixed mechanical connections. One of the main selected factors that ensure the economic effect is to improve the quality, static strength and durability of the structure, reducing the weight of the aircraft structure.

The analysis of modern methods and approaches of definition of economic indicators of new technics and technologies products introduction at the enterprise which help to predict the general economic effect is carried out. The comparative efficiency of the introduced technology is used in relation to the basic one, which is used at the enterprises of the branch. The components of the economic effect from the application of a pulse technologies and equipment set are determined and the approach to the economic effect calculations from the creation and improvement of pneumatic manual pulse device (PMPD) in computer-aided design (CAD) systems is formed.

In the course of the research methods for estimating the economic effect at introduction of new constructive and technological decisions of aircraft design and at application of a pulse technologies and equipment set, and also at application of PMPD CAD are offered. In comparison with similar known methods, the proposed approaches can minimize the time spent on calculations and increase the accuracy of their intended purpose. It provides an opportunity to demonstrate qualitatively the feasibility of using a pulse technologies and equipment set for unit assembly of aircraft structures with non-removable mechanical connections.

Here are some ways to evaluate the effectiveness of using a decision support system (DSS). DSS contains methods, models and algorithms for decision-making, software, databases and knowledge of the subject area and recommendations for the practical use of the results of the source information analysis. The factors influencing the economic result of the use of DSS in production are shown in the form of a scheme, where for the economic life of the investment in the creation of DSS 6 years commonly-accepted for CAD were selected.

Keywords: economic effect, complex of pulse technologies and equipment, aggregate assembly of aircraft.

Received date: 15.05 .2020

Accepted date: 01.07.2020

Published date: 31.10 .2020
Copyright (C) 2020, Vorobiov Iu., Maiorova K. This is an open access article under the CC BY license (http://creativecommons.org/licenses/by/4.0)

\section{Introduction}

In modern economic conditions, the use of the latest samples of aviation technology is due to an increase in the efficiency of their operation. The efficiency of the service life of the aircraft primarily depends on the increase in the service life of the aircraft airframe. Both parameters are determined mainly by the endurance of permanent mechanical joints (bolted, bolt-riveted and riveted joints) and the quality of the hole preparation for the formation of these joints. The use of static methods for the formation of these compounds is limited due to the large size, high cost, low productivity and low power-to-weight ratio of the equipment used. Impulse technologies and tools are free from these disadvantages. At the same time, impulse technologies, like static ones, ensure high process stability and product quality.

The design of modern aircraft and technological equipment (TE) of production is carried out using computer integrated $\mathrm{CAD} / \mathrm{CAM} / \mathrm{CAE} / \mathrm{PLM}$ technologies, and the manufacture of a significant part of their parts is carried out on CNC equipment (machine tools, machining centers, riveting machines, assembly and control equipment and etc.). However, most of the aggregate assembly operations, given the limited approaches to the assembly site, are carried out using a hand-held power tool (PT). At the same time, an important task is to select such a device that would satisfy the requirements for overall dimensions, energy, stability of energy parameters, safety and hygiene. This process can be facilitated and optimized by using an intelligent decision support system (DSS).

It should be noted that it is the use of the electronic structure of the product with the help of electronic models of connections that will reduce the labor intensity of technological preparation of production (TPP) while ensuring the visibility of the technological process (TP) for the aggregate assembly of aircraft. This can be provided by intelligent 
DSS when providing information support for the assembly of aircraft structures.

Based on the foregoing, when implementing the project for the implementation of a complex of impulse technologies and equipment for the aggregate assembly of aircraft structures based on DSS and computer-aided design systems $(\mathrm{CAD})$ is an urgent scientific problem and requires further solution.

\section{The object of research and its technological aduit}

The object of research is the economic effect of using a complex of impulse technologies and equipment for the aggregate assembly of aircraft structures with one-piece mechanical connections. The use of static methods at enterprises for the aggregate assembly of aircraft structures with one-piece mechanical joints is now limited due to the large dimensions, high cost, low productivity and low power-toweight ratio of the equipment used. However, this technology in production has been worked out over the years with a known economic effect, costs and profits. At the same time, impulse technologies, like static ones, provide high process stability and quality and are free from the disadvantages of static methods. The use of a complex of impulse technologies and equipment for the aggregate assembly of aircraft structures with one-piece mechanical connections will ensure the manufacturability of methods for setting fasteners with elastic-plastic interference, strengthening holes by surfaceplastic deformation, etc. the presence of an economic effect from the introduction of high technology.

Despite the listed advantages of pulse technologies, one of the most problematic areas is the correct identification of the main components, which are taken into account in the economic effect from the introduction of the latest pulse technologies and equipment for the aggregate assembly of aircraft structures at the enterprise in modern conditions. The problem can be attributed to poorly studied, which, in turn, provides a large field of activity for further research.

\section{The aim and objectives of research}

The aim of research is to develop methods that accurately highlight the economic effect of the implementation of a complex of impulse technologies and equipment for modular assembly of aircraft in modern conditions based on CAD and DSS. To achieve the set aim of research, the following objectives have been identified:

1. To analyze modern methods for determining the economic indicators of the introduction of new technology products.

2. To determine the main approaches for establishing integrated performance indicators (KPIs) from the implementation of a set of impulse technologies and equipment, CAD, pneumatic manual pulse device (PMPD), DSS for information support for the assembly of aircraft structures.

\section{Research of existing solutions of the problem}

4.1. Assessment of the economic effect of the implementation of new constructive and technological solutions. The existing methods for determining the economic indicators of the introduction of new technology products [1] do not always allow to identify the presence of an economic effect from the introduction of high technology. This is due to the complexity of the element-by-element calculation of the cost in the presence of expenses for research and development work.

So, in studies [2, 3], the relationship in the production of finance, strategy and marketing from the introduction of new technology at an enterprise is well covered, mathematical calculations and calculations are presented using the example of the United States and beyond, but does not depend on research and development, design work and the expected economic effect.

The works $[4,5]$ show structural changes in the production chain with new technologies and provide forecasts about the creation of restrictions and incentives for these innovations in the future, first of all, this is the gap between the methods of determining economic indicators and implementation technologies. So, the author of this work noted the importance of taking into account exactly the relative cost factors in assessing the actual characteristics from the introduction of new technologies, and not from their cost.

In the results of work [6], the economic effect is highlighted according to the selected criteria of the cost of equipping the basic and implemented impulse device for mandrel drilling. In [7], the theoretical, methodological and practical issues of the formation and development of the enterprise economy are consistently stated. The general organizational and economic characteristics of the enterprise as a business entity are given. The issues of formation and use of enterprise resources - personnel, tangible and intangible assets, investment resources are covered in detail. The main attention is paid to innovation processes, organization and regulation of the enterprise, financial and economic results and overall production efficiency, as well as to the anti-crisis management system. The general range of these studies should be narrowed down to solving situational problems when introducing new technologies or equipment into an existing well-functioning system of an enterprise's economy.

4.2. Assessment of the economic effect from the use of a complex of technologies and equipment. Studies [8, 9] show the dependence of the costs of introducing new technology and equipment on the production program, which is not profitable for low production volumes.

The paper [10] proposes a technical and economic modeling of the development of new technologies and equipment, which combines the parameters of processes with financial indicators that affect the profitability of new projects and technologies throughout the entire life cycle of the product. Technical and economic modeling preserves the information received at all stages of development, and later becomes the basis for making objective design and technological decisions. The paper shows how it is possible to achieve an economic effect on the basis of a single holistic model by constructing a user interface, based on the process model and calculations of the equipment parameters, and the assessment of capital and operating costs. Financial indicators in this case are associated with processes and economic parameters through a grid of correlations. The main disadvantage of this method of assessing the economic effect from the use of technology complexes and equipment is the need for high qualifications of the worker and the possibility of errors in calculations up to $30 \%$. 


\subsection{Assessment of the economic effect of the CAD use.} CAD effectiveness is manifested in three areas of human activity: device design, manufacture and operation.

In works [11, 12], it is shown in general terms that the use of CAD systems reduces the design time and reduces the complexity of work. Such evidence is most convincingly presented in studies [13, 14], which reflects the possibility of using CAD systems without their technical and economic analysis. That is, an increase in the effectiveness of activities is manifested in an increase in the annual volume of work or a decrease in the number of design buckets, but the advantages in the design and implementation of new devices into the existing CAD-based production system and with their subsequent use are not reflected.

In the field of creating impulse devices, savings are achieved by improving the quality of project documentation and engineering solutions, reducing the production time of impulse devices, reducing labor costs, consumption of materials, energy and other resources. In the field of operation of impulse devices designed by means of CAD, savings are achieved due to the improvement of the technical and economic indicators of facilities, and a reduction in operating costs.

4.4. Assessment of the economic effect of the DSS use. DSSs belong to a special class of information systems designed to assist decision-makers in their professional activities to use data, knowledge and models in preparing and making informed decisions.

As highlighted in $[15,16]$, DSS contains methods, models and algorithms for decision-making, software, databases and knowledge about the subject area and recommendations for using the results of the analysis of initial information in practice. The literature review $[17,18]$ presents a comparative study of various systems and approaches to the implementation of the DSS assessment process in order to determine the assessment methods. DSS are used to solve the problems of choosing the optimal alternative from a variety of available classifications, stratifications, ranking structurally complex objects, searching for bottlenecks in various processes, and multi-criteria expertise. Often these tasks are interrelated and complement each other, and among the results of data processing there is a rating of the alternatives under consideration. The use of DSS speeds up the process of reasoning and decision making.

According to the conclusions of the authors of [19], in practice, they use methods for assessing individual components of the DSS, but the problem of assessing the efficiency of the intellectual part of the DSS, containing the bases of models, rules, precedents, is little studied.

There are many methods and approaches that offer various options and methods that allow one to determine certain economic parameters, which can be predicted independently of each other for individual components of the economic effect from the latest implementations. With the help of examples, a set of these methods is generalized, but the influence on the economic effect of research works, both additional costs and the period of time, is not shown. All this requires a constructive connection for a specific research facility.

\section{Methods of research}

During the execution of the work, general scientific and special research methods were applied:

- analysis and synthesis - for preliminary analysis with the formation of the problem, the definition of research directions, the definition of the search area assumptions; determination of the main complex indicators of the economic effect and their sequence, which become components of the general indicators of the complex effect from the implementation of the research object; - analogies and comparative comparison - for determination of the characteristics of the implemented solutions, the ratio of costs and cost estimates relative to existing technologies at the enterprise.

\section{Research results}

6.1. Assessment of the economic effect from the introduction of new design and technological solutions for the aggregate assembly of aircraft structures. To determine the economic effect from the introduction of new design and technological solutions for the aggregate assembly of aircraft structures, the TP KPI was used in [5, 6]. KPIs are widely used and show their adequacy in functional and cost analysis, therefore, for impulse technology relative to the basic technology in the enterprise, which is identified with the ratio of the KPIs of these technologies:

$$
E=\frac{\Delta E}{\Delta K}=\frac{\left(C_{\text {year } . b}-C_{\text {year } . n}\right)}{\left(K_{n}-K_{b}\right)},
$$

where $\Delta E$ - savings or additional income for the year; $\Delta K-$ additional costs to obtain savings or additional profit for the year; $C_{\text {year. } b}, C_{\text {year. } n}$ - the cost of the annual volume of work on the new and basic technology; $K_{n}, K_{b}$ - capital expenditures for new and basic technology.

This approach is used when the use of alternative technologies or TE allows achieving the set aim. For example, to ensure that the required amount of riveting work is carried out at the appropriate enterprise in the preparation of any aircraft that can be considered similar to a known (basic) aircraft with a correction factor.

So, the annual volume of riveting work on a new aircraft can be determined by the formula:

$$
Q_{\text {year.n.aircraft }}=Q_{b} k N \text {, }
$$

where $Q_{b}$ - the number of riveting joints for the base aircraft, thousand pieces/product; $k$ - continuity coefficient of a new aircraft and a typical aircraft; $N$ - the estimated annual program for the production of new aircraft, the number of products.

The annual summarized costs for riveting options can be determined using the following formula:

$$
\begin{aligned}
& A_{\text {year n.aircraft }}^{r}=A_{n}^{r} Q_{\text {year n. aircraft }}^{r}+E_{n o r m} K_{n}, \\
& A_{\text {year b.aircraft }}^{r}=A_{b}^{r} Q_{\text {year n. aircraft }}^{r}+E_{\text {norm }} K_{b},
\end{aligned}
$$

where $A_{n}^{r}, A_{b}^{r}$ - the average technological cost of a riveting unit for a new and basic riveting technology, USD/piece; $Q_{\text {year n. aircraft }}^{r}$ the annual volume of riveting work in the preparation of a new aircraft, thousand pieces; $E_{\text {norm }}$ - the standard coefficient of economic efficiency in a region or at an enterprise (average return on capital).

The annual economic effect of replacing the basic version of the technology with a new one can be found as the difference between the reduced costs for the options, that is: 


$$
\begin{aligned}
& E_{\text {year }}=C_{b . \text { aircraft }}-C_{n \text {. aircraft }}=A_{n} Q_{n \text {. aircraft }}+E_{n} K_{n}- \\
& -C_{b} Q_{n \text {. aircraft }}+E_{n} K_{b .}=\left(C_{n}-C_{b}\right) Q_{n \text {. aircraft }}- \\
& -E_{n}\left(K_{n}-K_{b}\right)=\Delta E-E_{n} \Delta K,
\end{aligned}
$$

where $\Delta E-$ the annual savings from the use of the new technology in comparison with the basic one; $C$ - consolidated expenses; $\Delta K$ - additional investment in the implementation of a new technology.

And the comparative efficiency $E$ can be found by formula (1) with checking the condition $E>E_{n}$.

6.2. Assessment of the economic effect from the use of a complex of impulse technologies and equipment in the aggregate composition of aircraft. Analyzing the works [5, 6], the savings due to impulse riveting of titanium rivets will be determined as:

$$
E_{R T R}=E_{r m}+\Delta E_{c r}+E_{r e s},
$$

where $E_{r m}$ - the economic result of reducing the mass of the aircraft; $\Delta E_{c r}$ - reduction of costs for the annual estimate and the cost of the annual volume of work due to a decrease in the labor intensity of making connections; $E_{\text {res }}$ - annual savings due to increased connection life.

Fig. 1 shows the components of the economic effect of using a complex of impulse technologies. The results of these studies showed that it is also possible to calculate the savings due to the use of impulse setting of the rivet-bolt without a technological shank according to the formula:

$$
E_{r b}=E_{t i t}+E_{c . p r . B R}+E_{c . w}
$$

where $E_{t i t}$ - the annual savings of titanium alloys for bolt-rivet rods; $E_{\text {c. pr.BR }}$ - reducing the cost of bolt-rivets; $E_{c . \text {. }}$ - annual cost savings due to improved working conditions for workers.

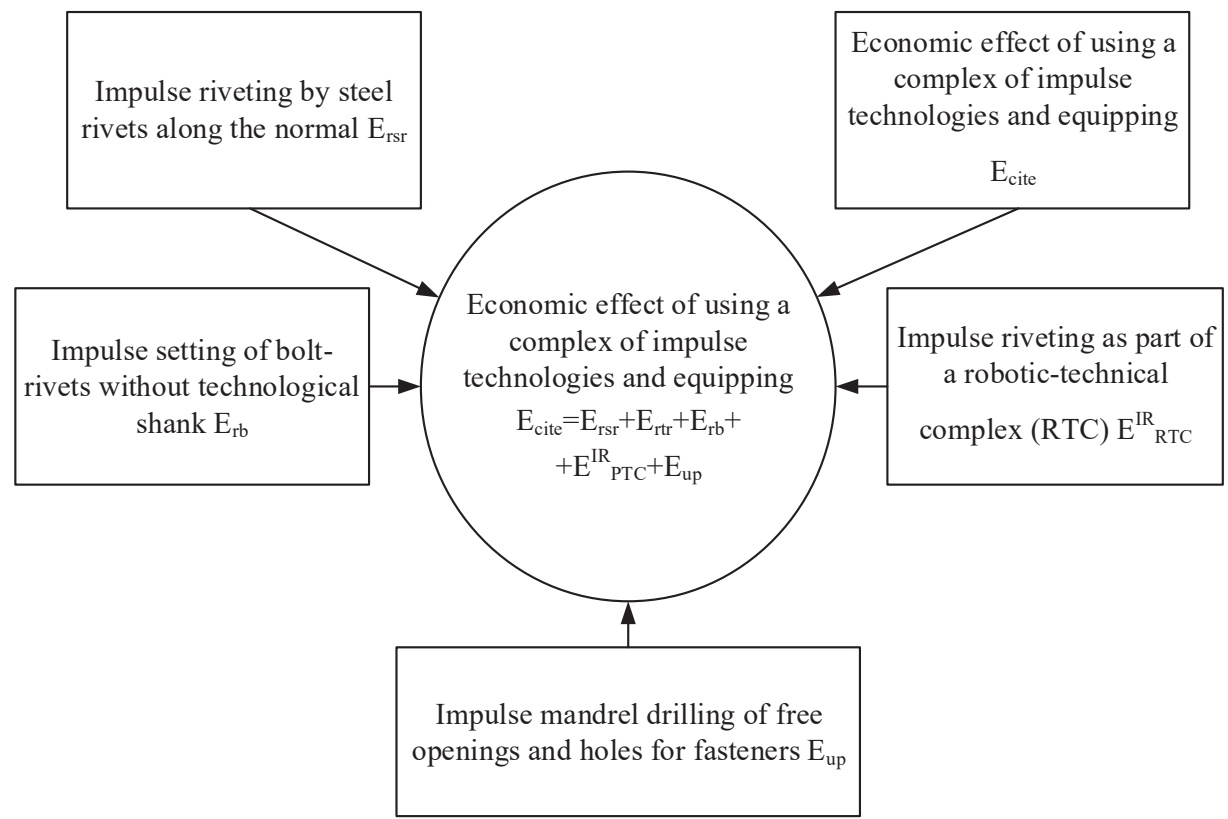

Fig. 1. Components of the economic effect from the use of a complex of impulse technologies and equipment [6]

$$
E_{R T C}=E_{I R}^{R T C}+E_{r e s}^{R T C}+E_{e q},
$$

where $E_{I R}^{R T C}$ - annual reduction in labor costs and deductions to funds due to the automation of the process of making connections in the conditions of a slipway assembly, a decrease in the labor intensity of assembly work and a reduction in the number of workers; $E_{r e s}^{R T C}$ - annual savings as a result of improved quality and resource of connections; $E_{e q}$ - annual reduction in equipment costs.

The savings due to impulse mandrel drilling of free openings and holes for fasteners per year will be:

$$
E_{M D F O H F}=E_{s . h}+E_{c}+E_{t}+E_{C B}+E_{c . a i r}+E_{c . w},
$$

where $E_{s . h .}-$ annual savings as a result of reducing the labor intensity of strengthening the holes; $E_{c}$ - savings due to a decrease in the cost of an energy carrier for an annual volume of work (for basic equipment); $E_{C B}$ - annual savings in the use of implementation in comparison with the baseline due to a decrease in the number of performers, reduction of auxiliary time; $E_{t}$ - annual savings for reducing the cost of the tools; $E_{c \text { cair }}$ - annual savings in compressed air (for basic equipment). follows.

The components of formulas (5)-(9) can be calculated as

Annual savings from replacing highly scarce and expensive rivets with core and steel rivets:

$$
E_{r}=\left(P_{r . c}-P_{r . s}\right) N_{r},
$$

where $P_{r . c .}-$ the price of a rivet with a core; $P_{r . s}$ - steel rivet price; $N_{r}$ - the need for rivets for the annual volume of work. Annual cost reduction for special tool manufacturing:

$$
E_{s . t}=P_{s . t}^{b . e} \cdot n_{s . t}^{b . e}-P_{s . t}^{n . e} \cdot n_{s . t}^{n . e},
$$

where $P_{s . t}^{b . e}$ - unit price of a special tool for rivets with a core (basic equipment); $n_{s . t}^{b e}-$ the amount of special tools required for the annual volume, which can be found through the wear resistance $P_{s . t}^{b . e}$ and the annual demand for rivets $N_{r}$ :

$$
n_{s . t}^{b e}=\frac{N_{r}}{P_{s . t}^{b e}},
$$

where $P_{s . t}^{b . e}$ - the unit price of special tools for rivets made of corrosion-resistant steel (new equipment); $n_{s . t}^{b . e}-$ the amount of special tools required for the annual volume, which can be found through the wear resistance $P_{s, t}^{b . e}$ and the annual demand for rivets $N_{r}$ :

$$
n_{s . t}^{b e}=\frac{N_{\text {end }}}{P_{s . t}^{b e}} .
$$

A similar saving on impulse riveting as part of a robotictechnical complex (RTC) in a slipway assembly can be calculated using the formula:
Improving working conditions can be in an increase in productivity, as well as in a decrease in the category of work, on which the prices for performing maintenance depend: 


$$
\begin{aligned}
& E_{I R}^{c w w}=T^{b} \cdot l_{h}^{b} \cdot\left(1+H_{c o n}\right)\left(1+H_{a d}\right)- \\
& -T^{n} \cdot l_{h}^{n} \cdot\left(1+H_{c o n}\right)\left(1+H_{a d}\right),
\end{aligned}
$$

where $T^{b}, T^{n}$ - annual labor intensity of work in the basic and new technology options, respectively; $l_{h}^{b}, l_{h}^{B}-$ hourly wage rate corresponding to the average category of work in the basic and new technology options, respectively; $H_{\text {con }}$ - the coefficient of contributions to employment funds, social and pension insurance $\left(H_{c o n}=0.37\right) ; H_{a d}-$ the coefficient of additional wages $\left(H_{a d}=0.2-0.3\right)$.

The economic result from a decrease in the mass of an aircraft of the An-124 type (Ukraine) due to the use of impulse riveting with titanium rivets for formula (6) consists of savings from a decrease in the cost of transportation of $E_{c . t}$ and additional profit from an increase in the volume of transportation $\Delta P$, which is calculated in accordance with [6] according to the formula:

$$
\begin{aligned}
& E_{r m}=n_{\text {aircraft }}\left(E_{c . t}+\Delta P\right)= \\
& =\left[\begin{array}{l}
\Delta C_{t \cdot k m}(Q+\Delta Q) \cdot V \cdot K_{q} \cdot H+ \\
+\Delta Q \cdot K_{q} \cdot V \cdot H \cdot P_{t \cdot k m}
\end{array}\right] n_{\text {aircraft }},
\end{aligned}
$$

where $n_{\text {aircraft }}$ - the average annual number of operated aircraft of this type, pcs.; $\Delta C_{t \cdot k m}$ - reduction of the prime cost of 1 ton. $\mathrm{km}$ on the An-124 aircraft as a result of reducing the weight of the airframe; $Q$ - basic payload of AN-124 type aircraft; $\Delta Q-$ an increase in the payload as a result of a decrease in the mass of the aircraft airframe; $V$ - cruising speed of AN-124 type aircraft; $K_{q}$ - the average utilization factor of the commercial load of the aircraft (0.6-0.8); FT - the average annual flight time of the An-124 type aircraft, hours (1500-2000 h/year) $P_{t \cdot k m}$ - the rate of profit for transportation (usually $10 \%$ of cost of $1 \mathrm{t} \cdot \mathrm{km}$ for this type of aircraft [6]).

Reducing the cost of the annual estimate and the cost of the annual volume of work due to a decrease in the labor intensity of the compounds $\Delta E_{c c}$ for formula (3) can be calculated using the following formula:

$$
\Delta E_{c c}=\Delta T l_{h}^{r}\left(1+H_{c o n}\right)\left(1+H_{a d}\right),
$$

where $\Delta T$ - the annual saving in labor intensity of the work of making connections due to the impulse riveting of titanium rivets, standard hours; $l_{h}^{r}$ - hourly tariff rate corresponding to the category of work with riveting of titanium rivets, USD/standard-hour.

Annual savings as a result of increased connection life can occur with an increase in the amortization life of the aircraft airframe, if possible as a result of the use of titanium rivets. The calculation is made according to the formula:

$$
E_{\text {res }}=\left(\frac{P_{a f}}{T_{a . r}^{b}}-\frac{P_{a f}}{T_{a m . r}^{n}}\right) H n_{\text {aircraft }},
$$

where $P_{a f}$ - the price of an aircraft airframe of the corresponding type, USD; $T_{a . r}^{b}$ and $T_{a . r}^{n}$ - amortization resource of an aircraft airframe of the corresponding type with basic and new technologies, h; $H$ - average annual flying time of an aircraft of the corresponding type, h; $n_{\text {aircraft }}$ - the average annual number of aircraft of the corresponding type operated by airlines, pcs.
The components for calculating the $E_{R B}$ are determined as follows. Annual savings of titanium alloys for boltrivet rods:

$$
E_{\text {tit }}=\Delta M N_{b r} P_{\text {tit }} m_{\text {aircraft }},
$$

where $\Delta M$ - the weight saving of the titanium bar due to the use of bolt-rivets without a technological shank (2.170 kg/1000 bolt-rivets); $N_{B R}$ - the number of boltrivets in the airframe structure of an aircraft of the corresponding type, thousand pieces; $C_{t i t}$ - the cost of a bar made of titanium alloy VT16 (14 USD $/ \mathrm{kg}) ; m_{\text {aircraft }}$ - the average number of aircraft gliders of the corresponding type, manufactured per year, pcs.

Reducing the labor intensity of the manufacture of bolt-rivets from titanium and the cost of work per year are found by the formula:

$$
E_{\text {cost pr } B R}=\Delta t_{B R} N_{B R} m_{\text {aircraft }} l_{B R}\left(1+K_{a d}\right)\left(1+K_{\text {con }}\right),
$$

where $\Delta t_{B R}$ - the saving of labor costs for the manufacture of bolt-rivets from VT16 titanium, standard hours; $t_{B R}-$ hourly tariff rate of the corresponding category of work for the manufacture of bolt-rivets, USD/standard-hour.

Improving working conditions when using pneumatic impulse hammers, for example, MPI-90M (Ukraine) compared to a magnetic impulse installation (MIU) for riveting, for example, NN503 (Ukraine), allows to increase labor productivity and reduce the loss of working time due to their temporary disability:

$$
\begin{aligned}
& E_{c . w}=P_{p r} n_{w}+\Delta t_{t j n t} N_{B R} m_{\text {aircraft }} l_{B R} \times \\
& \times\left(1+K_{a d}\right)\left(1+K_{c o n}\right)+\Delta T_{i} \bar{W}_{\text {day }},
\end{aligned}
$$

where $P_{p r}$ - the cost of providing protection and screens from the effects of high-voltage currents and magnetic fields per MIU, USD/piece; $n_{w}$ - the number of workplaces where the MIU installation is used, pcs.; $\Delta t_{t j n t}-$ a decrease due to the improvement of working conditions of a technically justified norm of time for performing work on installing a bolt-rivet, $\mathrm{h} ; \Delta T_{i}$ - reduction of losses of working time due to improved working conditions during assembly, peoplexdays; $W_{d a y}$ - the average daily wages of a worker at the assembly (riveters), USD/day.

To calculate the terms of the economic result of using impulse riveting as part of the RTC under the conditions of the slipway assembly $E_{R T C}$, a similar approach is used, as in formula (14), where, according to a new version of the assembly technology, the use of RTC is assumed:

$$
\begin{aligned}
& E_{I R}^{R T C}=T^{b} \cdot l_{h}^{b} \cdot\left(1+H_{c o n}\right)\left(1+H_{a d}\right)- \\
& -T^{R T C} \cdot l_{h}^{R T C} \cdot\left(1+H_{c o n}\right)\left(1+H_{a d}\right) .
\end{aligned}
$$

The economic result of improving the quality and resource of connections can be estimated by the formula (17), if this allows to increase the amortization resource of the aircraft airframe.

Reduced equipment costs:

$$
E_{e . c}=P_{e c}^{b}-P_{e . c}^{R T C},
$$

where $P_{e . c}^{b}, P_{e . c}^{R T C}$ - basic volume of equipment costs for the year and the annual amount of equipment costs in the KEC conditions, USD. 
The economic result of impulse mandrel drilling of free openings and holes for fasteners, according to formula (9), has a number of separate components that require a number of calculations in accordance with economic efficiency factors.

When strengthening the holes and reducing the complexity of this operation, the economic result can be calculated similarly to formula (14):

$$
E_{U P_{0}}=\frac{\left(t^{b}-t^{n}\right) N_{h} m_{\text {aircraft }}}{360} l_{h}^{m}\left(1+H_{c o n}\right)\left(1+H_{a d}\right),
$$

where $t^{b}$ - labor intensity of mandrel holes in the conditions of using the MIU, $t^{b}=12 \mathrm{~s} ; t^{n}$ - labor intensity of mandrel in conditions of using pneumo-pulse tool $t^{n}=6 \mathrm{~s}$; $N_{h}$ - the number of free holes in the aircraft airframe requiring mandrel drilling, pcs.; $m_{\text {aircraft }}$ - the average number of aircraft gliders of the corresponding type manufactured per year, pcs.; $l_{h}^{m}$ - the average hourly rate for the execution of mandrel operations in accordance with the category of work, USD/hour.

Reducing the cost of energy in terms of the annual volume of work on mandrel can be found as:

$$
E_{\text {car }}^{d}=\left(P_{\text {car }}^{b}-P_{\text {car }}^{n}\right) N_{h} m_{\text {aircraft }},
$$

where $P_{c a r}^{b}$ - price of the energy carrier for MIU-P1 (Russia) to strengthen one hole, dollars; $P_{c a r}^{n}-$ price of energy carrier for PIUD-90 (Ukraine) to strengthen one hole, $P_{\text {car }}^{n}=0.000032$ USD.

The decrease in the cost of the tool in the conditions of using PIUD-90 instead of MIU-P1 can be defined as follows:

$$
E_{t}=\left(C_{t}^{b}-C_{t}^{n}\right) n_{d}
$$

where $P_{t}^{b}$ - the price of MIU-P1 (12,000 USD); $C_{t}^{n}-$ the price of PIUD-90 (1100 USD); $n_{d}$ - the number of devices for mandrel holes required to ensure the annual volume of work, pcs.

Conversion from US dollars into the national currency of the country can be carried out at the official exchange rate for interbank transactions at the date of settlement.

The annual savings from the use of pneumatic pulse devices PIUD-90 (Ukraine) for mandrel drilling in comparison with a machine for installing bolts of the MSZ-1.5 type with a pneumohydraulic pump-multiplier PGNM1-250 (Russia) is calculated using a formula similar to formula (23):

$$
E_{U P o}=\frac{\left(t^{b}-t^{n}\right) N_{h} m_{\text {aircrft }}}{360} l_{h}^{m}\left(1+H_{\text {con }}\right)\left(1+H_{d}\right),
$$

where $t^{b}$ - the labor intensity of mandrel drilling with the MSZ-1.5 machine, $t^{b}=30 \mathrm{~s}$; $t^{n}$ - labor intensity of mandrel holes for PIUD-90, $t^{n}=6 \mathrm{~s}$.

Annual savings in compressed air when using PIUD-90 compared to MSZ-1.5:

$$
E_{c . a}=\left(P_{b}-P n\right) N_{c y c l e} P_{c . a},
$$

where $P_{b}$ - the cost of compressed air when using MSZ-1.5 (Ukraine), $P_{b}=0.076 \mathrm{~m}^{3} /$ cycle; $P_{n}-$ compressed air consumption when using PIUD-90, $P_{n}=0.002 \mathrm{~m}^{3} /$ cycle; $N_{\text {cycle }}-$ annual number of hole mandrel cycles; $P_{c . a}-$ compressed air price, $\mathrm{USD} / \mathrm{m}^{3}$.
The decrease in the cost of the tool when using the PIUD-90 instead of the MSZ-1.5 is calculated similarly to the formula (25):

$$
E_{d}=\left(C_{d}^{b}-C_{d}^{n}\right) n_{d},
$$

where $C_{d}^{b}$ - the price of MSZ-1.5 with a pneumohydraulic pump-multiplier PGNM1-250 (3385 USD); $C_{d}^{n}$ - the price of PIUD-90 (1100 USD); $n_{d}$ - the number of devices used per year, pcs.

It is possible to improve working conditions when using PIUD-90 instead of MSZ-1.5, but additional research is needed to assess the economic result. Since the difference in the weight of the devices is negligible $(1.5 \mathrm{~kg})$, although the pneumohydraulic drive as a whole has a weight of $14.6 \mathrm{~kg}$, which makes maneuverability somewhat difficult.

6.3. Assessment of the economic effect of the use of PMPD CAD. The system of basic indicators for PMPD CAD is identical to the system of indicators of the economic efficiency of research and development (R\&D) and experimental design $(R \& D)$, that is, it is the annual economic effect $E_{t}$, the integral effect $E_{\text {int }}$ and the coefficient of overall economic efficiency $E$.

The annual economic effect can be found by the formula:

$$
E_{t}=\left(\Delta C_{t}+E_{\text {man.t }}+E_{o . t}\right)-E_{N}\left(K_{p r}+\Delta K\right),
$$

but to take into account the time factor, it is necessary to calculate like this:

$$
E_{t}=\Delta C_{t}+E_{\text {man. }}+E_{o . t}-K_{p r t}-\Delta K_{t},
$$

where $\Delta C_{t}-$ cost reduction of design of impulse devices in the $t$-th year; $E_{\text {man. } t}$ - savings in the $t$-th year from reducing the cost of manufacturing pulse devices designed by $\mathrm{CAD} ; E_{\text {o. } t}$ - savings from reduced operating costs for impulse devices that were designed by CAD; $K_{p r . t}-$ production costs for the creation of PMPD CAD; $\Delta K_{t}$ - additional capital investments for PMPD CAD (training of workers, cost of trial operation, etc.).

The amount of the annual economic effect is distributed among all participants in the development, implementation and application of PMPD CAD.

To make an economic decision on the feasibility of creating a PMPD CAD system and justify the feasibility of financing this event, it is necessary to calculate the integral effect for the corresponding settlement period, since the decision made from individual annual indicators may be erroneous. This effect consists of the sum of the annual economic effects over the life of the PMPD CAD system. The service life of the PMPD CAD system in the first modernization is taken at the level of 6 years. Thus, the integral effect:

$$
E_{\text {int }}=\sum_{t=1}^{6} E_{t} \alpha_{t}+E_{\text {add }}
$$

where $E_{t}$ - the annual economic effect of the $t$-th year of creation and operation of the PMPD CAD system; $E_{\text {add }}-$ additional profit from early commissioning of the aircraft due to the shortening of the aircraft TPP and the use of PMPD CAD; $\alpha_{t}-$ the coefficient of time reduction. 
The coefficient of the overall economic efficiency of PMPD CAD can be calculated as follows:

$$
E=\frac{E_{i n t}}{6\left(K_{p r}+\Delta K\right)},
$$

or

$$
E=\frac{\left(\Delta E+E_{p r}+E_{o}\right)}{\left(K_{p r}+\Delta K\right)},
$$

after which the condition $E>E_{n}$ must be checked.

Now let's consider in more detail the calculation of the components of the annual effect $E_{t}$.

Reducing the cost of design is determined by the formula:

$$
\Delta C_{t}=\Delta Q_{t} W_{d}\left(1+H_{c o n}\right)-W_{t},
$$

where $\Delta Q_{t}$ - the reduction in labor costs for design in the estimated year $t$, peoplexdays; $W_{d}$ - average daily wages of a designer, taking into account additional payments; $H_{c o n}$ - the coefficient of contributions to funds (pension, social insurance and employment); $W_{t}-$ annual costs of the $t$-th year for the operation of the PMPD CAD system.

The annual savings from reducing the manufacturing cost (estimated cost) of PMPD, which are designed by CAD means, with a technological cycle of the $j$-th product less than one year, are calculated as follows:

$$
E_{p r}=\sum_{j=1}^{m t} E_{s . j} N_{j t}
$$

where $E_{s . j}$ - specific savings from reducing the cost of manufacturing a design object of the $j$-th type; $N_{j t}$ - the annual program for the manufacture of objects of the $j$-th type in the $t$-th year; $m t$ - product range of year $t$.

The total annual savings from reduced operating costs at CAD-designed facilities are calculated as:

$$
E_{o . t}=\sum_{j=1}^{Z_{t}} E_{o . j} N_{j t},
$$

where $E_{o . j}$ - annual savings from reducing operating costs at the $j$-th facility; $N_{j t}$ - the number of $j$-th facilities operated in the $t$-th year; $Z_{t}$ - nomenclature of objects operated in the $t$-th year.

Additional profit from early commissioning of design objects is calculated by the formula:

$$
E_{\text {add }}=E_{n}\left(K_{p r}+\Delta K\right) \Delta t+\sum_{j} \Pi_{j} N_{j} \Delta t_{j},
$$

where $E_{n}$ - standard efficiency coefficient; $K_{p r}$ - total production costs for the creation of PMPD CAD; $\Delta K-$ additional investments of the organization on PMPD CAD; $\Delta t$ - the average period of early commissioning of PMPD CAD, years; $P_{j}$ - the annual income from the operation of the aircraft, for the manufacture of which PMPD CAD was used; $N_{j}$ - the number of $j$-th aircraft put into operation ahead of schedule; $\Delta t_{j}$ - the period of early commissioning of the $j$-th aircraft, for which PMPD CAD was used, years.

To take into account the influence of the time factor when determining the effects or costs, it should be remembered that when calculating the coefficient of reduction in time, taking into account formula (31):

$$
\alpha_{t}=\left(1+E_{n}\right)^{\left(t_{p}-t\right)} \text {. }
$$

The estimated year should be chosen depending on which indicator needs to be brought together in time. It is necessary to find out whether this indicator is maximized or minimized, since in the case of choosing the first year as the calculated one, the reduction factor $\alpha_{t}$ will be less than one, since the degree $\left(t_{p}-t\right)$ gives a negative number. And vice versa: when applied as a calculation period, the last year, the degree of formula (37) will be positive and the coefficient $\alpha_{t}$ will have a value greater than one, except for the last year, for which $\left(t_{p}-t\right)=0$, and, accord-

\begin{tabular}{|c|c|c|}
\hline $\begin{array}{l}\text { Name and essence of approaches } \\
\text { to assessing the effectiveness of DSS }\end{array}$ & Advantages & Disadvantages \\
\hline $\begin{array}{l}\text { Evaluation of the DSS economic efficiency of } \\
\text { software by comparing the economic effect of } \\
\text { the development (implementation) of software } \\
\text { with the cost of its creation (acquisition) }\end{array}$ & $\begin{array}{l}\text { It is taken into account to what extent the implementation of the } \\
\text { DSS software allowed reducing the number of analysts' jobs and } \\
\text { getting savings on their salaries. This method is widely known } \\
\text { and is applicable not only to DSS, but also to any software }\end{array}$ & $\begin{array}{l}\text { It is difficult to separate the effect obtained } \\
\text { as a result of using software from the effect } \\
\text { obtained by other activities and the external } \\
\text { environment }\end{array}$ \\
\hline $\begin{array}{l}\text { Assessment of the DSS time efficiency (how } \\
\text { much the DSS allows to reduce the time spent } \\
\text { on processing the initial data for making a de- } \\
\text { cision and justifying the optimal decision) }\end{array}$ & $\begin{array}{l}\text { This approach is easy to use, it is possible to use test tasks to } \\
\text { get the result before putting the system into operation }\end{array}$ & Does not include cost indicators \\
\hline $\begin{array}{l}\text { Assessment of the DSS quality, in this case it } \\
\text { is determined to what extent the requirements } \\
\text { of the users of the DSS are satisfied in rela- } \\
\text { tion to the capabilities of the manufacturers } \\
\text { and the tasks set by the DSS designers. The } \\
\text { set-theoretic approach is used to calculate the } \\
\text { DSS quality indicator }\end{array}$ & $\begin{array}{l}\text { Allows to determine the ways of revision, adaptation or develop- } \\
\text { ment of the system, and in some cases - ways to reduce the } \\
\text { cost of its creation and increase economic efficiency }\end{array}$ & $\begin{array}{l}\text { There is a certain subjectivity of assessment, } \\
\text { satisfaction of requirements may be different } \\
\text { for different people of the same profession. } \\
\text { Does not include cost indicators }\end{array}$ \\
\hline $\begin{array}{l}\text { Assessment of the DSS economic efficiency } \\
\text { by comparing the financial results obtained } \\
\text { directly from the decisions made with the costs } \\
\text { of creating (acquiring) the DSS }\end{array}$ & $\begin{array}{l}\text { This method is used if the system is designed to support decision- } \\
\text { making, the result of the implementation of which allows to make } \\
\text { a profit in monetary terms in the short term }\end{array}$ & $\begin{array}{l}\text { The efficiency calculated in this way will } \\
\text { change dynamically depending on the num- } \\
\text { ber of successful or unsuccessful decisions } \\
\text { that gave a profit or loss, respectively }\end{array}$ \\
\hline
\end{tabular}
ingly, $\alpha_{t}=1$.

6.4. Assessment of the economic effect of the DSS use. Table 1 shows some directions for assessing the effectiveness of the DSS.

Directions for assessing the effectiveness of the decision support system [19] 
DSS is a complex task and requires a special approach, therefore it is necessary:

- identify $i$-th factors of economic efficiency of using such a system;

- for each individual $i$-th factor, develop (or use) a methodology for calculating the cost result from the use of the $P_{i}$ system;

- find the integral cost result of the $t$-th year of application of the decision support system:

$$
P_{t}=\sum_{i=1}^{n} P_{i},
$$

where $P_{i}$ - the result for the $i$-th factor; calculate the costs that must be made to achieve the result for the $i$-th factor $C_{i}$; find the integral costs:

$$
C_{t}=\sum_{i=1}^{n} C_{\mathrm{i}}
$$

- the integral effect for the service life of $T_{s}$ or for the calculation period is determined by the formula:

$$
E_{\text {in }}=\sum_{t=1}^{T_{s}}\left(P_{t}-C_{t}\right) \alpha_{t},
$$

where $P_{t}-$ the total cost result of the $t$-th year; $\alpha_{t}-$ discount coefficient of the $t$-th year.

The service life of the $T_{s}$ project is taken from $6-10$ years.

The simple return on SRR can be found through averages, as the ratio:

$$
S R R=\frac{\sum_{t=1}^{T_{s}}\left(P_{t}-C_{t}\right)}{T_{s} \cdot K},
$$

where $K$ - the total investment in the DSS.

Received should be greater than $\mathrm{SRRE}_{\text {norm }}$.

The factors influencing the economic result of the DSS use are presented as a diagram in Fig. 2.

Thus, for each $t$-th year, the annual economic result consists of the following components:

$$
E_{t}^{D S S}=E_{t}^{T S}+E_{t}^{D}+E_{t}^{C}+E_{t}^{R}+E_{t}^{F T}+E_{t}^{A P}+E_{t}^{O}+E_{t}^{C R} .
$$

The annual economic result of the DSS use depends on the volume of DSS use and the volume of operation of equipment produced in the DSS conditions.

For the economic life of investments in the DSS creation, which can be taken at the level of 6 years adopted for $\mathrm{CAD}$, the total result can be found taking into account the time factor by the formula:

$$
E_{\Sigma}^{D S S}=\sum_{t=1}^{6} E_{t}^{D S S} \alpha_{t} .
$$

Special coefficient:

$$
\alpha_{t}=1 /\left(1+E_{s}\right)^{1-t},
$$

where $E_{s}$ - the standard for bringing multi-temporal costs equal to $0.08[6] ; t$ is the reference period ( $t$-th year).

Calculated by the formula (44) the coefficients $\alpha_{t}$ have the following values for the corresponding years: the first year -1.0 ; the second -0.926 ; third -0.857 ; fourth 0.793 ; fifth -0.734 ; sixth -0.680 .

The average annual indicator of the economic result of DSS use is found by the formula:

$$
E_{A A}^{D S S}=\frac{E_{\Sigma}^{D S S}}{6} \text {. }
$$

The ratio of this average annual result to capital investments in the creation of a DSS will allow to assess the economic efficiency of these costs:

$$
E=\frac{E_{A A}^{D S S}}{K}
$$

The resulting value of $E$ must be higher than the standard, that is, the condition $E>E_{n}$ must be met.

To take into account the time factor, if the period for creating the DSS and the costs of its creation last more than a year, then taking into account the time factor will consist in adding to the amounts actually spent (capital investments).

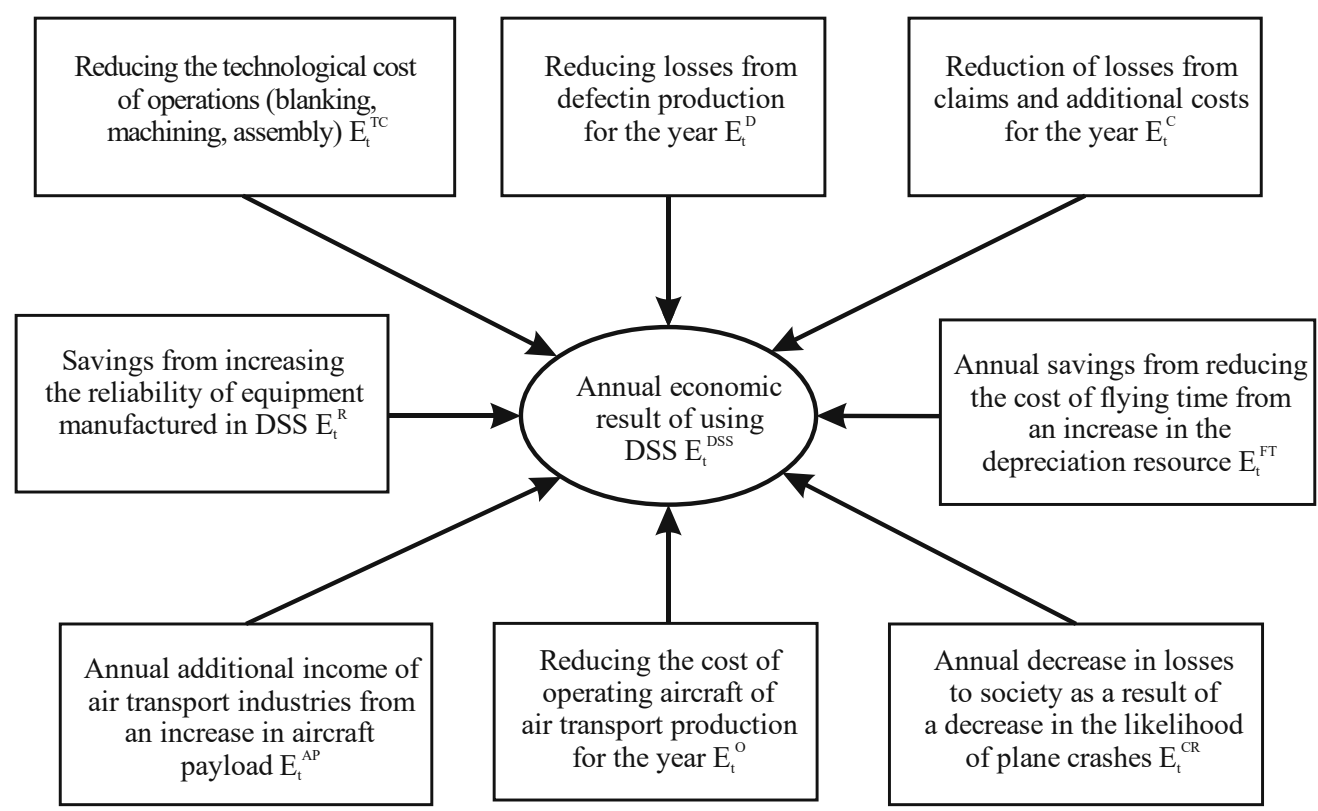

Fig. 2. Factors of economic efficiency and components of economic result of application of decision support system [19] 
It should also be added the lost profit from the fact that the invested funds were withdrawn from circulation (withdrawn from accounts) and did not give the interest specified in the financial institution. Thus, taking into account compounding, the value $K^{\prime}$ can be found by the formula:

$$
K^{\prime}=\sum_{t=1}^{t_{C l}} K_{t}\left(1+E_{s}\right)^{t}
$$

where $t_{C I}$ - capital investment turnover for the reference period ( $t$-th year); $K_{t}$ - the amount of investments in the $t$-th year; $E_{s}$ - the standard for bringing multi-temporal costs equal to 0.08 .

Using this $K^{\prime}$ in formula (47) will worsen the indicator $E$, but the time factor is taken into account.

\section{SWOT analysis of research results}

Strengths. The strengths of the study and application of the proposed calculation methods for assessing the economic effect of the introduction of a research facility is that they can be used in CAD systems for aircraft production, regardless of the product release program. The provided approaches can be used to predict the profitability of implementation, highlight the minimization of costs associated with the implementation of other projects in the field of information technology, DSS, etc. Compared to analogs, the proposed study allows to predict possible risks and costs, thereby eliminating the factor of surprise.

So, the proposed methods allow:

- if the minimum cost is used as a criterion for choosing the best option for solving the problem, then the information on time leads to the last year of the billing period. Then the option with a shorter investment period and the option according to which significant expenses are carried out closer to the estimated year will be more acceptable; - if the maximum profit is used as a criterion for choosing the best option for solving the problem, then these indicators of different times lead to the first year of the calculation period, that is, until the year of the start of funding. Then the option with a shorter period of obtaining the effect and the option according to which a greater effect is achieved in the coming years will be more acceptable.

Weaknesses. To calculate the values of the components of the annual economic result $\mathrm{E}$ for each component of the amount, a calculation method must be submitted, and after filling these theoretical aspects with specific numerical indicators, a specific result can be obtained.

The analysis of the proposed methods for assessing the economic effect of the introduction of the object under study has made it possible to identify their shortcomings, in particular, the complexity and duration of their introduction into automated systems and the need to ensure many indicators in the calculations.

Opportunities. It should be noted that in the future, the methods for assessing the economic effect of the implemented object can be supplemented with modules of problem-oriented software packages, which are usually based on the developed mathematical apparatus. Such software can be modernized, including elements of adaptive algorithms, and can be used for mobile use to solve a wide range of tasks related to the flexibility of data entry corrections for certain research indicators from the introduction of innovations in production.

Threats. Threats to the computational methods for assessing the economic effect can be attributed to the fact that even the proposed approaches are not a technology that allows, with high accuracy, with an error of no more than $5 \%$, to obtain results from the introduction of new technologies in aircraft production.

\section{Conclusions}

1. The analysis of methods and approaches for assessing the economic effect of using products of new equipment and technology is done. The main characteristics of the implementation and the established KPIs are determined. The economic effect is provided mainly by reducing the labor intensity of making connections, increasing the durability of the structure, reducing the mass of the aircraft due to the replacement of bolt-riveted and riveted bolt connections, saving expensive materials. In addition, the results of the economic effect are influenced by a decrease in the cost and material consumption of assembly processes' TE, a decrease in the labor intensity and terms of TPP, and an improvement in working conditions for workers.

2. A set of methods and a sequence of approaches to calculating the economic effect of introducing a complex of impulse technologies and equipment, PMPD CAD, DSS for information support for the assembly of aircraft structures and ontological DSS for the choice of hand-held pulse devices have been determined. These methods and approaches can take into account the peculiarities of production and be used in the CAD system throughout the entire life cycle of the aircraft structure.

\section{References}

1. Samochkin, V. N., Pronin, Iu. B., Logacheva, E. N. (2000) Gibkoe razvitie predpriiatiia: Effektivnost $i$ biudzhetirovanie. Moscow: Delo, 352.

2. Cabral, L. (2000). Introduction to industrial organization. Cambridge: MIT Press, 424.

3. Church, J., Ware, R. (2000). Industrial organization. A strategic approach. Boston: Irwin McGraw-Hill. Available at: https:// edisciplinas.usp.br/pluginfile.php/1663633/mod_resource/content/1/ChurchWare.pdf

4. Antonelli, C. (2004). The Economics of Innovation, New Technologies and Structural Change. Torino, 78.

5. Tochilin, P. V., Sagatelian, G. R., Nazarov, Iu. F. (2001). Metodika rascheta ekonomicheskoi effektivnosti vnedreniia naukoemkikh tekhnologii. MGOU-XXI-Novye tekhnologii, 1, 29-34.

6. Vorobev, Iu. A. (2003). Opredelenie ekonomicheskoi effektivnosti vnedreniia tekhnologii impulsnoi klepki. Aviatsiino-kosmichna tekhnika i tekhnologiia, 1 (36), 76-81.

7. Pokropyvnyi, S. F. (Ed.) (2006). Ekonomika pidpryiemstva. Kyiv: KNEU, 350.

8. Tönissen, S. (2014). Economic Efficiency of Manufacturing Technology Integration. Aachen: Apprimus Verlag. Available at: https://core.ac.uk/download/pdf/36618919.pdf

9. Petrou, A.; Michalos, A. C. (Eds.) (2014). Economic Efficiency. Encyclopedia of Quality of Life and Well-Being Research. Dordrecht: Springer, 1793-1794. doi: http://doi.org/10.1007/97894-007-0753-5_818

10. Burk, C. (2018). Techno-Economic Modeling for New Techno$\log y$ Development. The Global Home of Chemical Engineers. Available at: https://www.aiche.org/resources/publications/ cep/2018/january/techno-economic-modeling-new-technologydevelopment

11. Tönissen, S., Rey, J., Klocke, F. (2015). Economic efficiency of manufacturing technology integration. Journal of Manufacturing Systems, 37, 173-181. doi: http://doi.org/10.1016/ j.jmsy.2015.07.003

12. Richter, A. (2013). Economic Advantages by CAD/CAM Use in Compound with Production Data Organization. Digital Product and Process Development Systems: IFIP TC 5 International Conference. NEW PROLAMAT. Dresden, 53-60 
13. Chang, K.-H. (2013). Product Manufacturing and Cost Estimating Using $C A D / C A E$. Academic Press, 570. doi: http://doi. org/10.1016/c2012-0-00833-2

14. Yifu Lin, J., Liu, P. (2020). Inclusive catch-up: the new structural economics approach. Recovering better: economic and social challenges and opportunities A compilation of the High-level Advisory Board on Economic and Social Affairs, 52-68.

15. Pick, R. A., Weatherholt, N. (2012). A Review On Evaluation And Benefits Of Decision Support Systems. Review of Business Information Systems (RBIS), 17 (1), 7-20. doi: http:/ doi.org/10.19030/rbis.v17i1.7580

16. Lin, J. Y. (2013). New structural economics. doi: http://doi. org/10.1596/978-0-8213-8955-3

17. Boukhayma, K., ElManouar, A. (2015). Evaluating decision support systems. 15th International Conference on Intelligent Systems Design and Applications (ISDA). Marrakech: IEEE. doi: http://doi.org/10.1109/isda.2015.7489263
18. Boukhayma, K., Ben Hiba, L., Elmanouar, A. (2019). DSS success: The intertwining of satisfaction and learning. The ArabWIC 6th Annual International Conference Research Track. doi: http://doi.org/10.1145/3333165.3333174

19. Vinodh, S., Jayakrishna, K., Kumar, V., Dutta, R. (2013). Development of decision support system for sustainability evaluation: a case study. Clean Technologies and Environmental Policy, 16 (1), 163-174. doi: http://doi.org/10.1007/s10098-013-0613-7

Vorobiov Iuriy, PhD, Vice Rector, National Aerospace University «Kharkiv Aviation Institute», Ukraine, e-mail:yuriy.vorobyov@gmail.com, ORCID: https://orcid.org/0000-0001-6401-7790

Maiorova Kateryna, PhD, Associate Professor, Department of Aircraft Manufacturing Technologies, National Aerospace University «Kharkiv Aviation Institute», Ukraine, e-mail:kate.majorova@ukr.net, ORCID: https://orcid.org/0000-0003-3949-0791 